\title{
Vertical Coordination as an Opportunity for Market Risk Management in Agricultural Holdings in Bulgaria
}

\author{
Assoc. Prof. Dr. Tanya Georgieva \\ University of Economics - Varna, Varna, Bulgaria \\ t.georgieva@ue-varna.bg
}

\begin{abstract}
The purpose of this article is to assess the impact of the Common Agricultural Policy on the potential of agricultural producers in Bulgaria to manage price risk through a vertical coordination strategy. A comparison was made between the established producer organizations in Bulgaria and other Member States of the European Union on the main indicators of the level of development - number of recognized organizations, organization rate and average number of members. It is concluded that the policy objective of reducing producer price volatility through vertical coordination along the supply chain has not been achieved at this stage. In order to make it possible for the market (including price) risk to be managed by farmers in Bulgaria in this way, it is necessary to seriously increase the share of farms that cooperate for the purpose of joint sale of products, as well as to increase the size of established producer organizations.
\end{abstract}

Keywords: market risk, agriculture, producer organizations, vertical coordination

JEL Code: Q1 DOI: https://doi.org/10.36997/IJUSV-ESS/2020.9.3.127

\section{Въведение}

Липсата на прозрачност на пазара, неравенството в пазарната сила и понякога - антиконкурентното поведение на големите компании надолу по веригата на доставки на храни пораждат опасения относно ценовия риск, пред който са изправени земеделските стопани. По тази причина, Общата селскостопанска политика на Европейски съюз включва комплекс от инструменти за намаляване на нестабилността на цените на селскостопанските пазари. Едно от направленията на тази политика е насьрчаване на секторното коопериране между производители на селскостопанска продукция. Очаква се това да повиши договорната им сила и да създаде предпоставки за вертикална координация с други участници по веригата за доставки на храни. В същото време, в България липсват традиции в доброволното стопанско сдружаване между земеделски стопани. Това повдига въпроса за реакцията на производителите на селскостопанска продукция на политическите стимули и успеха на предприетите политически мерки.

Целта на статията е да се оцени влиянието на Общата селскостопанска политика върху потенциала на производителите на селскостопанска продукция в България да управляват ценовия риск посредством стратегия на вертикална координация.

\section{1. Вертикалната координация като стратегия за управление на риска в земеделието}

Вертикалната координация се отнася до синхронизиране на последователните етапи на производството и търговията по отношение на количеството, качеството и сроковете на доставка. Методите на вертикална координация отразяват различна степен, в която една фирма в даден етап на производство на краен продукт упражнява контрол върху количеството и качеството на продукцията в другите етапи. Те включват договорно производство и вертикална интеграция, които се различават помежду си по спектьра на контролираните дейности от контрагента (или т. нар.,интегратор”, фиг. 1).

При отвореното производство фирмата не се ангажира с продажба на продукцията си преди завършване на производството. Пазарните цени координират трансфера на ресурси през различните етапи на производството. Фермерството в България традиционно се осъществява в отворена производствена система, където ресурсите се купуват и продуктите 
се продават от производителя при цена, определена по време на покупката. В Европейски съюз прилагането на отворено производство в селското стопанство през последните години намалява, за сметка на установяването на вертикална координация между участниците в стойностната верига, поради следните основни причини: 1) повишаване на изискванията на индустриалните потребители на земеделски продукти към качеството на стоките и процеса на доставка; 2) усъвършенстването на технологиите, което позволява повишаване степента на диференциация на продуктите; 3) повишаване на договорната сила на земеделските стопани. Договорното производство предполага по-висока степен на взаимодействие между продавача и купувача, в сравнение с отвореното производство. От друга страна, за разлика от вертикалната интеграция, при него отделните субекти, които обезпечават дейностите по веригата на стойността, запазват самостоятелното си съществуване.

\begin{tabular}{|c|c|c|c|}
\hline Least & & & Most \\
\hline Open & $\begin{array}{l}\text { Market- } \\
\text { specific } \\
\text { contract } \\
\text { (or marketing } \\
\text { contract) }\end{array}$ & $\begin{array}{l}\text { Resource-providing } \\
\text { contract } \\
\text { (or } \quad \text { production } \\
\text { contract) }\end{array}$ & $\begin{array}{r}\text { Vertical } \\
\text { integration }\end{array}$ \\
\hline
\end{tabular}

Фиг. 1. Методи на вертикална координация, според спектъра на контролираните дейности от контрагента (интегратора)

Source: Steve W. Martinez (2002) p. 2

Предварителните споразумения за продажба на селскостопанска продукция (т. нар. форуардни договори) са писмено или устно споразумение между купувач и производител, което определя цена (или метод за ценообразуване) и/или гарантира пазарна реализация на стоката преди прибиране на реколтата. Форуардният договор, като споразумение между фермер (или група от фермери) и купувач, се счита за средство за управление на риска, тъй като чрез него земеделските стопани могат да осигурят сигурна реализация на продукцията, по-слаба изменчивост на цените на производител и в някои случаи - дори сигурна цена. Степента и начина по който тези инструменти променят риска зависи от конкретните условия, съответно - от вида на договора. В практиката на земеделските стопанства в Европейски съюз са се утвърдили четири основни вида форуардни договори, а именно договор за пазарна цена, договор за пул, договор с минимална цена и договор с фиксирана цена (ЕС, 2017, p. 167).

\section{2. Кооперирането за съвместна реализация на продукцията като предпоставка за предварителни ценови споразумения в земеделието}

България е една от петте държави-членки на Европейски съюз (заедно с Чехия, Словакия, Малта и Кипър), в които земеделските стопани не управляват риска посредством договаряне на бъдещи доставки с останалите участници по веригата за производство и доставки на храни. Най-често срещаният тип форуарден договор в държавите-членки на Европейски съюз, е договаряне на фиксирана цена (ЕС, 2017). Като цяло, възприемането на форуардни договори е сравнително високо за секторите и държавите-членки, в които земеделските производители са по-организирани в организации на производители или кооперативи (EC, 2017, p. 167). Държавите от Северна и Западна Европа, като Франция, Германия, Обединеното кралство, Холандия, Австрия и Дания, над 50 \% от фермерите са 
членове на кооперации на земеделски производители. В Австрия членството във фермерски обединения дори е задължително (Loughrey, J. et.al, 2016, p. 17). Кооперативните структури в тези страни предлагат на пазара над $40 \%$, а в някои случаи и над $50 \%$ от селскостопанските продукти. Средиземноморските държави Италия и Португалия имат интензивност на членството в кооперативи от около $30 \%$ до 50\%. В зависимост от бранша, фермерите в Португалия и Италия предлагат на пазара от $25 \%$ до над $50 \%$ от селскостопанските продукти чрез кооперации (Borst, A, 2017, p.4). В Португалия петте най-големи земеделски кооперативи са организирани в млечния сектор. Пазарният дял на тези структури е над 70 \% (Rabelo J., 2015). Страните от Централна и Източна Европа, обикновено имат най-нисък процент на интензивност на членството заради историческото наследство и изградената култура на предпазливост към сътрудничеството между производители. Все пак, изследвания покзават, че т.нар. „дефицит на кооперативни нагласи и доверие в икономики след преход“ (Lissowska, M., 2012) във все по-голяма степен се преодолява в част от страните - членки. В Литва, Естония и Унгария съвместната реализация на продукцията е сред най-често предоставяните услуги от страна на функциониращите кооперативни организации в различни подсектори на селското стопанство (Sumyle, D, 2017; MRA, 2020; Imre F., 2002) Съществуват доказателства (Bijman J., 2012), че приблизително 40\% от оборота на земеделските стопани в ЕС-27 се реализира посредством кооперативи. Дельт е най-нисък в България, Люксембург и Кипър.

Връзката между (хоризонталното) коопериране между земеделски стопани за съвместна реализация на продукцията и успешното им (вертикално) координиране с други участници по веригата за производство и доставки на храни може да се обясни с повишаване на договорната сила на земеделските стопани и намаляване на транзакционните разходи за преработвателите на храни и търговците в резултат на сдружаването на производителите. Компаниите, които оперират "надолу" по веригата на доставки - преработватели, тьрговски вериги и т.н. нямат интерес да договарят бъдещи доставки на селскостопанска продукция с малки земеделски стопанства, ако няма добре организирани структури, които обединяват тези производители. Това е така, защото форуардното договаряне между големи клиенти и много на брой сравнително дребни земеделски стопани в повечето случаи изисква посредник - обединяваща/кооперативна структура - който да осигури търсеното от клиента количество продукция с изискваното качество при приемливи за преработвателя/търговеца общи разходи по сключването на сделки. В много случаи тези кооперативни организации или организации на производители, освен че предоставят на земеделските стопани информация относно търсените продукти (напр. конкретни сортове растения) и осигуряват сигурност относно реализацията на продукцията и ценовия марж на земеделския стопанин, изграждат точки за опаковане с общ бранд (Sherman D. et. al, 2005). По този начин кооперирането на земеделските стопани намалява пазарния риск и като добавя стойност към продукцията. Ако няма добре организирани обединяващи структури (групи производители, кооперативи) е налице сериозен дисбаланс в договорната сила на преработвателите и земеделските стопани: индустрията има пазарна власт, която и позволява да купува според потребностите си и пазарната цена, което е причина за сравнително висока степен на изменчивост на цените на производител.

\section{3. Инструменти на европейската политика за подкрепа на организациите на производители и приложението им в България}

С цел по-справедливо разпределение на добавената стойност във веригата за доставки на храни и укрепване на общите способности на земеделските стопани за водене на преговори, включително сключване на смекчаващи риска ценови споразумения, Европейски съюз подкрепя земеделските стопани, които желаят да работят заедно в организации на 
производители в съответствие с общите разпоредби на Регламент (ЕС) № 1308/2013, Делегиран регламент (ЕС) 2016/232. Подкрепата се реализира като от една страна признати организации на производители (ОП) се освобождават от някои забрани в областта на конкуренцията, а от друга страна - създадените обединения на производители имат възможност да получат финансова подкрепа по двата стълба на Общата селскостопанска политика.

Очаква се тези организации да повишат договорната сила на земеделските стопани основно чрез: концентриране на предлагането; съобразяване на предлагането с търсеното качество; предоставяне на техническа и логистична помощ на членовете си, подпомагане при управлението на качеството;. трансфер на знания; съдействие за сключване на договори за доставки (включително форуардни договори) между земеделските стопани и други участници във веригата за доставки (на база на освобожденията съгласно правото в областта на конкуренцията (Регламент (ЕС) № 1308/2013, чл. 152).

Наред с освобождаването си от забраната за съгласуване на цени и условия по сделките, създалите организация производители имат възможност да получат финансова подкрепа от европейските фондове. При това, размерьт на подпомагането по двата стълба на ОСП зависи от стойността на реализираната продукция т.е. колкото по-голяма е стойността на реализираната продукция от една организация, толкова по-голям е размера на финансовата подкрепа, която те получава. По този начин се възнаграждават приоритетно групите, които обединяват повече, по-големи и/ или по-производителни земеделски стопанства. Това е така за да се реализира целта на подпомагането - подобряване на пазарните позиции на производителите чрез предлагане на значително по-голям стойностен размер продукция от този, който отделния земеделски стопанин може да предложи.

Признатите организации на производители (ОП) в сектор "Плодове и зеленчуци" могат да получават финансово подпомагане по пазарни мерки от Европейския фонд за гарантиране на земеделието (ЕФГЗ). Основна форма за финансово подпомагане на ОП са разработени от тях оперативни програми, които в България се одобряват от Държавен фонд „Земеделие” - Разплащателна агенция. Оперативната програма представлява инвестиционна програма с период на изпълнение от 3 до 5 години, която си поставя поне две цели от определените в чл. 33 на Регламент 1308/2013. Всяка от целите произтича от основната идея на подпомагането, а именно - повишаване на договорната сила на земеделските стопани и следователно - повишаване на пазарната цена и понижаване на ценовия риск. Изпълнението на оперативната програма се обезпечава с оперативен фонд, който се финансира от вноски на членовете на организацията, вноски на самата организация и от финансова помощ от ЕФГЗ. Размерът на собственото участие на организацията на производители в оперативния фонд е най-малко 40\%. Помощта от Европейски фонд за гарантиране на земеделието (ЕФГЗ ) е до 4,6\% от стойността на предлаганата на пазара продукция от ОП. В повечето държавичленки на Европейски съюз степента на организираност на земеделските стопани в сектор "Плодове и зеленчуци" (измерена като дял на продукцията, предложена на пазара от организации на производители в общия стойностен размер на предложената продукция от производителите в сектора) е сравнително висока и това е единствената подкрепа, която организациите на производители получават. В България се прилага изключение за държавичленки, в които делът на продукцията, предлагана от организации на производители е особено нисък (Регламент (ЕС) № 1308/2013, чл. 35). Затова в Наредба № 11/2007г. са включени разпоредби за прилагане на правилата на ЕC за допълнително национално съфинансиране на оперативния фонд. Националната финансова помощ може да бъде в размер до $80 \%$ от средствата, набрани от членовете или от самата ОП, но не повече от 25\% от годишната стойност на реализираната на пазара продукция и от левовата равностойност на 1500000 евро. Обвързването на подкрепата със стойността на предложената на пазара 
продукция демотивира организациите на производители в България да участват в тази форма на подкрепа - през повечето от години на периода 2009 -2018 г. в страната се изпълнява само една оперативна програма. Това е така поради сравнително ниския оборот на организациите. Броят на изпълняваните оперативни програми нараства през 2018 г.- от общо 13 признати ОП в сектор "Плодове и зеленчуци" (MAFF, 2020), четири ОП изпълняват оперативни програми, с общо одобрен оперативен фонд на стойност 15568579 лева (MAFF, 2019).

Интересът на организациите на производители към подкрепата по Стълб 2 на ОСП е значително по-голям. Сред възможните причини за това са следните: първо, за разлика от помощта по Стълб 1 на ОСП, която е предназначена само за организации на производители на плодове и зеленчуци, изпълняващи оперативни програми, по Стълб 2 се подкрепят признати организации и групи на производители от всички сектори; второ, финансирането по Мярка 9 "Учредяване на групи и организации на производители", за разлика от подкрепата на оперативните програми, е изцяло публично (не се изисква съучастие); трето, размерът на субсидията, както и при оперативните програми, зависи от стойността на предлаганата на пазара продукция, но се определя при по-висок процент - изчислява се за всяка от петте години като процент от стойността на предлаганата на пазара продукция през предходната година и намалява от 10\% за първата до $8 \%$ за петата година Допустими за подпомагане са административни разходи, свързани със създаването, признаването и функциониране на ОП и групи производители (ГП). През периода 15 юни - 4 септември 2018 г. е обявен първият прием на заявления за подпомагане по мярката, с бюджет в размер на 14 793044 лева (MAFF, 2019, p. 94). Подадени са 40 проектни предложения на стойност 11.5 млн. евро. За сравнение, общият брой на организациите и групите производители през 2018 г. е 70 (MAFF, 2020), което означава, че повече от половината признати организации и групи производители са имали интерес към подкрепата.

\section{4. Степен на развитие на организациите на производители в България}

Основна част от организациите на производители в България (91\% ) са признати през периода 2015 - 2019 г. (фигура 2)

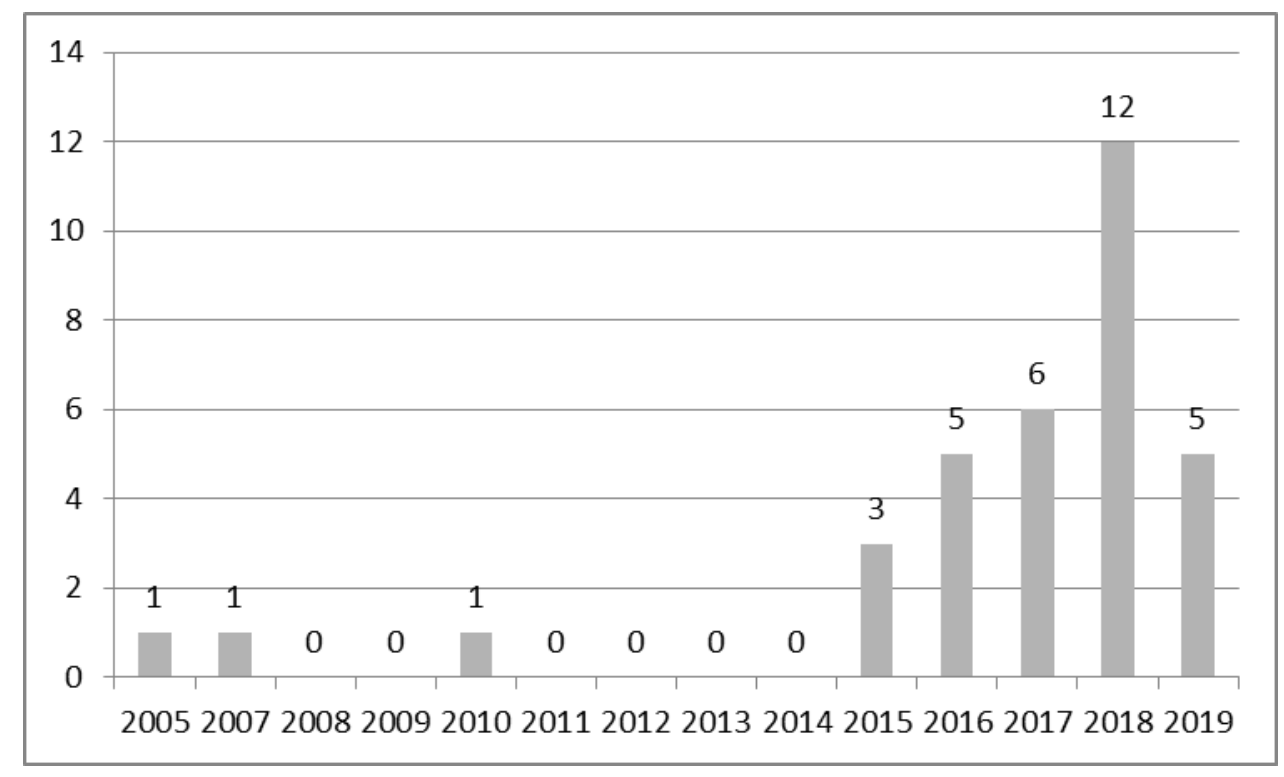

Фигура 2. Брой организации на производители по година на признаване, 2005 2019 г.

Източник: MAFF, 2020 
В рамките на последните две години на периода броят на тези структури в страната нараства двойно. Към 2018 г. България е на междинна позиция в Европейски съюз (четиринадесето място) по отношение на броя признати организации на производители като значително изостава от водещите по този показател Франция, Германия, Италия и Испания. За сравнение, тези обединения в България са 17, а във Франция - 724. В седем държавитечленки на Европейски съюз оперират повече от 100 организации (ЕС, 2020).

Сред основните показатели, които се използват за оценка на степента на развитие на организациите на производители, които земеделските стопани създават в дадена държава или подсектор на земеделието в страната е т. нар. "степен на организираност (organization rate)" (EC, 2018, p. 16), като за обозначаване на този индикатор се използва още терминът "икономическа тежест (economic weight)" (EC, 2019). Степента на организираност се изразява като относителен дял на предложената на пазара продукция от организации на производители в общия стойностен размер на продукцията на земеделските стопани в сектора/страната.

През 2016 г. в рамките на държавите-членки, в които функционират признати организации, организациите на производители на плодове и зеленчуци (най-голямата група, която обхваща повече от половината организации в България) са на последно място в Европейски съюз по този показател - фигура. 3.

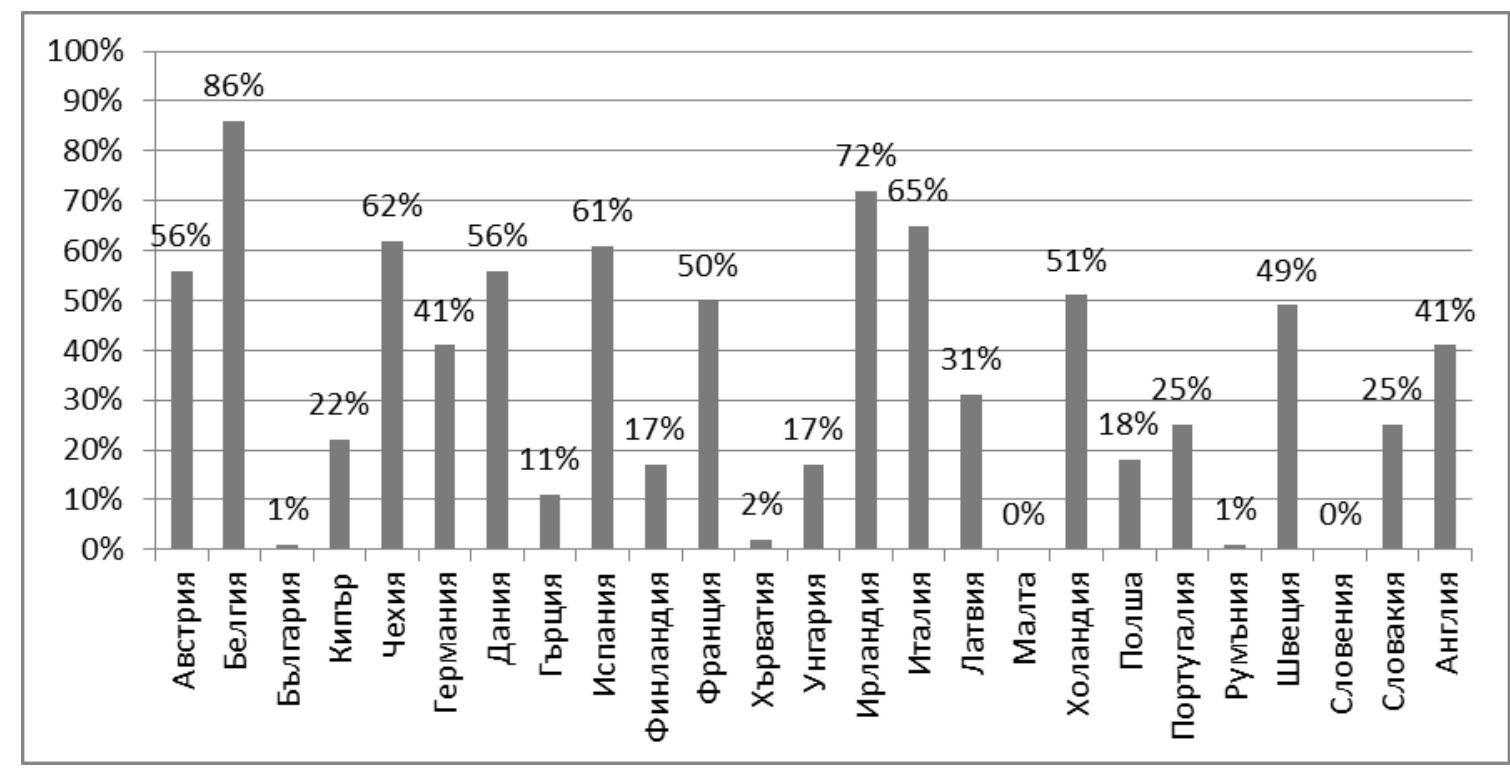

Фигура 3 Степен на организираност на производителите на плодове и зеленчуци в държавите-членки на Европейски съюз, 2016 г.

Източник: EC, 2018, p. 16

При това, в някои държави много по-малък брой обединения на производители успяват да реализират значително по-голям дял от стойностния размер на създадената в сектора продукция. В Ирландия и Дания по две организации реализират съответно 72\% и $56 \%$ от предложените на пазара в страната плодове и зеленчуци. В България осем организации реализират $1 \%$ от продукцията. 


\section{ИЗВЕСТИЯ НА СЬЮЗА НА УЧЕНИТЕ - ВАРНА}

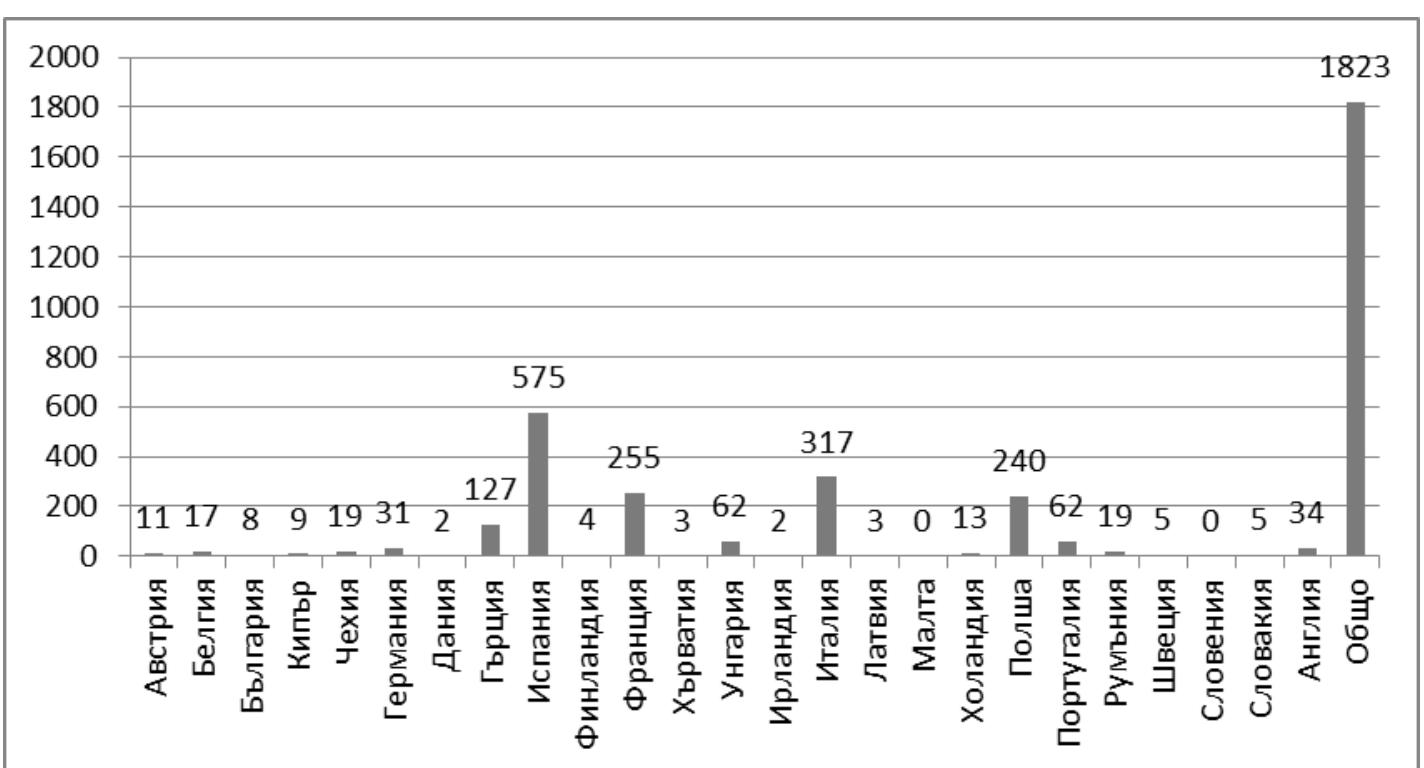

Фигура 4. Брой организации и асоциации на организации на производители на плодове и зеленчуци в държавите-членки на Европейски съюз, 2016 г.

Източник: EC, 2018, p. 16

Ниската степен на организираност на организациите на производители в България може да се обясни с малкия дял на производителите, които се обединяват в организации и малкия среден брой членове на една организация, както и на обстоятелството, че някои законови ограничения в страната демотивират големите стопанства да участват в тези обединения (например ограничението от максимум 40\% дял в гласовете при вземане на решения, независимо от дела в капитала).

Около $0,07 \%$ от земеделските стопанства в България участват в организации на производители (броят на членовете на признатите в страната организации на производители е 145 (2017 г.) при общ брой на земеделските стопанства 201014 през 2016 г.).

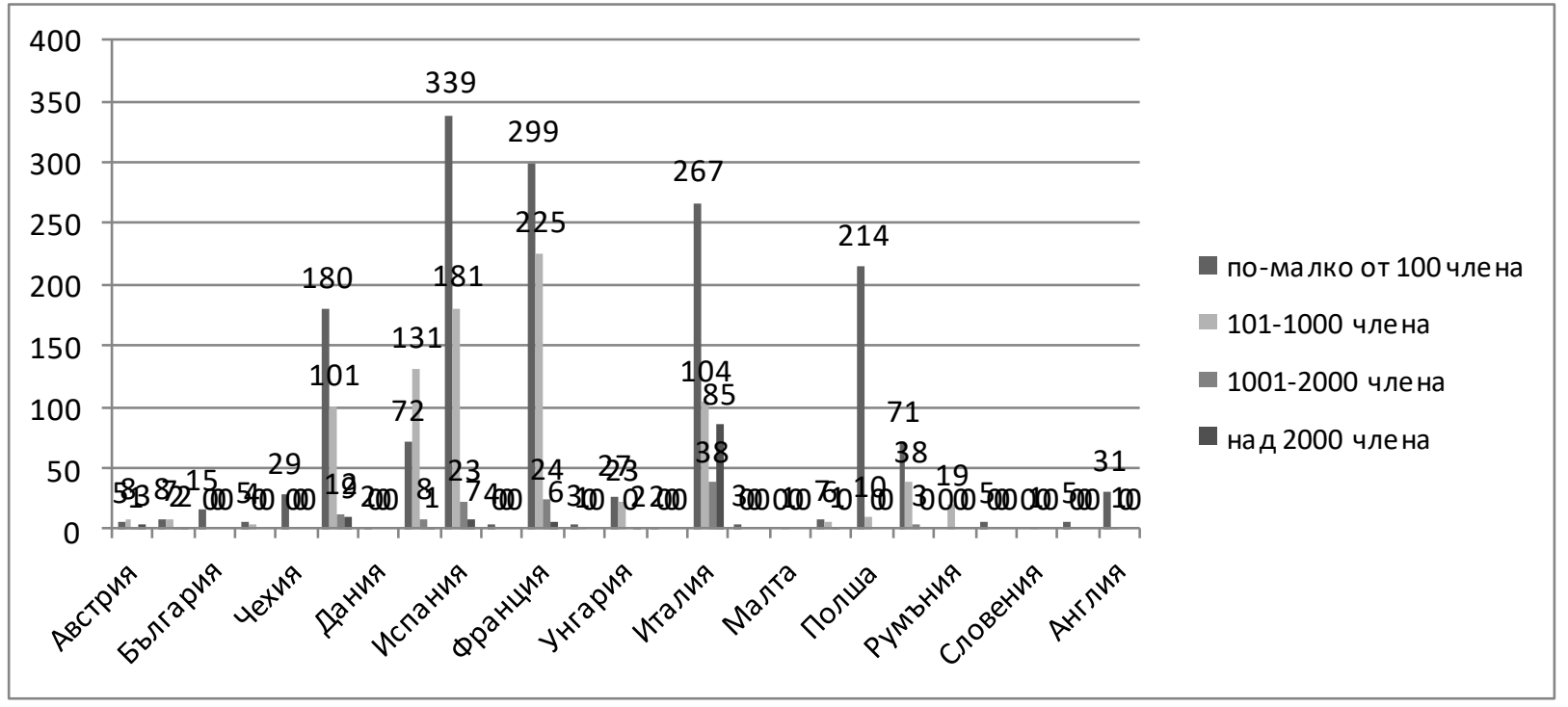

Фигура 5. Размер (брой членове) на признати организации на производители и асоциации на организации на производители по брой организации и по държави-членки, 2017 г.

Източник: ЕC, 2019, p. 48 
България е част от по-малката група страни-членки на Европейски съюз, в които няма функционираща организация на производители на земеделска продукция, включваща повече от 100 члена - фигура 5. Останалите държави, които през 2017 г. попадат в тази група са Чехия, Дания, Ирландия, Финландия, Латвия, Швеция и Словакия (EC, 2019, p. 48).

В рамките на групата държави, в които всички признати организации включват помалко от 100 члена. (2017 г.) България е една от страните с най-голям брой признати организации на производители - 19 броя. Признатите организации на производители в Дания и Ирландия са 2, във Финландия са 4, в Латвия, Швеция и Словакия са по 5. По този показател България е изпреварена само от Чехия, в която са признати 45 организации. Наред със сравнително големия си брой, опериращите в България организации се отличават с наймальк среден брой членове - 8 бр., който е доста близък до минималния, необходим за признаване на едно такова обединение в страната. Например в сектор "Плодове и зеленчуци" най-голямата организация (и най-старата) има 27 члена, а втората по големина - 16 члена. Останалите организации са с брой членове близо до минимално изисквания за признаване (MAFF, 2018, p. 15), Оценени по брой членове, организациите в Дания, Швеция, Финландия, Ирландия и Чехия са значително по-големи и обединяват за съвместна работа средно от 25 (Чехия) до 54 (Дания) броя ферми (ЕС, 2019).

\section{Заключение}

Земеделските стопани в повечето държави-членки на Европейски съюз прилагат стратегия на вертикална координация, за да осигурят стабилност и приемливи равнища на цените на производител. Фермерите в тези държави успяват да създадат структури, посредством които целят да обединят доставките си при очакваното от клиентите качество и по този начин да повишат своята договорна сила при преговори с тьрговци или преработватели. Производителите на селскостопанска продукция в България имат достьп до европейски субсидии за създаването и развитието на такива обединяващи структури организации на производители. В резултат на това, през последните години нараства броят на създадените стопански обединения в страната, но целта на подкрепата на този етап не се реализира - не са установени практики по предварително договаряне на условията по сделките между земеделски стопани и участници "надолу" по веригата за доставки на храни. Основна причина за това е ограниченият капацитет на новосъздадените структури - делът на продукцията на организациите на производители в общия стойностен размер на предлаганата на пазара продукция е относително малък. Това от своя страна се дължи на сравнително малкия дял на стопанствата, които вземат участие в тези обединения и относително малкия среден брой членове на една организация, както и на обстоятелството, че стопанствата със сравнително висок ресурсен статус не са мотивирани да се кооперират с по-малки. За да стане възможно пазарният (включително ценови) риск да бъде управляван от земеделските стопани в страната посредством вертикална координация, е необходимо сериозно да нарасне делът на стопанствата, които се кооперират с цел съвместна реализация на продукция, както и да се повиши размерът (разбиран като брой членове) на създадените организации на производители.

\section{References}

1. Bijman, J., Iliopoulos, C., Poppe, K. J., Gijselinckx, C., Hagedorn, K., Hanisch, M.\& Van Der Sangen, G. (2012). Support for farmers' cooperatives: Final report European Commission.

2. Borst, A. (2017) Agricultural Production Cooperatives in the EU: Explaining Variation in Cooperative Development Honors Theses. 21. [Online] Available from: https://egrove.olemiss.edu/hon_thesis/21 [Accessed 07/08/2020].

3. European Commission (2017) Study on risk management in EU Agriculture. Final Report 
Directorate-General for Agriculture and Rural Development

4. Imre, S. (2002) Vertical Co-ordanitaion in Transition Agriculture: a Hungarian Cooperative Case Study, RePEc Discussion papers 2002/12/01

5. Lissowska, M. (2012). The deficit of cooperative attitudes and trust in post-transition economies. Paper presented at the 16th Annual Conference of the International Society for New Institutional Economics, California, June 14-16, 2012.

6. Loughrey, J. \& Donnellan, T. (2016). Farm Size Inequality and the Market Power of Farmers in Western Europe. Conference: 153rd European Association of Agricultural Economists Seminar

7. Ministry of Agriculture, Food and Forestry/MAFF (2020) Priznati ot ministara na zemedelieto, hranite $i$ gorite grupi i organizacii na proizvoditeli [Online] Available from: https://www.mzh.government.bg [Accessed 07/08/2020].

8. Ministry of Agriculture, Food and Forestry (2019) Godishen doklad za sastoyanieto i razvitieto na zemedelieto [Online] Available from: https://www.mzh.government.bg [Accessed 07/08/2020].

9. Ministry of Agriculture, Food and Forestry (2018) Nacionalna strategiya za ustoichivi operativni programi na organizacii na proizvoditeli za perioda 2017 - 2021 g. Izmenena i adaptirana spryamo zakonodatelstvoto na ES. MAFF

10. Ministry of Rural Affairs/MRA (2020) Estonian agriculture cooperatives featured in Dutch journal. [Online] Available from: https://www.agri.ee/en/news/estonian-agriculturecooperatives-featured-dutch-journal [Accessed 18/10/2020]

11. Rebelo, J., \& Caldas, J. (2015). The Economic Role of the Portuguese Agricultural Cooperatives. Revista de Economia e Sociologia Rural, 53(Suppl. 1), pp. 91-102.

12. Sumyle, D., Ribašauskienè, E. (2017) Servitization of Lithuanian agricultural cooperatives. Management Theory and Studies for Rural Business and Infrastructure Development. Vol. 39, 2017/12/27, pp. 510-523

13. Shermain D. Hardesty (2005) Cooperatives as Marketers of Branded Products Journal of Food Distribution Research 36(1), pp.237-242

14. Steve W. Martinez (2002) Vertical Coordination of Marketing Systems: Lessons From the Poultry, Egg, and Pork Industries. Agricultural Economic Report No 807, 2012. US Department of Agriculture

15. European Commission (2020) Producer and interbranch organizations. [Online] Available from: https://ec.europa.eu/info/food-farming-fisheries/key-policies/common-agricultural-

policy/market-measures/agri-food-supply-chain/producer-and-interbranch-organisations_en [Accessed 07/08/2020].

16. European Commission (2018) The application of the Union competition rules to the agricultural sector $\{\mathrm{COM}(2018) 706$ final $\}$ Commission Staff Working Document Accompanying the document Report from the Commission to the European Parliament and the Council

17. European Commission (2019) Study of the best ways for producer organizations to be formed, carry out their activities and be supported. Annexes May 2019 Directorate-General for Agriculture and Rural Development 